\title{
Late onset Leber's optic neuropathy: a case confused with ischaemic optic neuropathy.
}

\author{
F-X Borruat, W T Green, E M Graham, M G Sweeney, J A Morgan-Hughes, M D Sanders
}

\begin{abstract}
A case is reported of a 63-year-old man with progressive central visual loss in one eye followed 11 months later by involvement of the fellow eye. A diagnosis of chronic ischaemic optic neuropathy was considered. However, despite a negative family history, the absence of electrocardiographic abnormalities, and minimal fundus changes a diagnosis of Leber's optic neuropathy was made on the basis of magnetic resonance imaging findings and the mitochondrial DNA mutation at base pair 11778.
\end{abstract}

(Br F Ophthalmol 1992; 76: 571-573)

The National Hospital for Neurology and

Neurosurgery, Neuro-

Ophthamology Unit,

Queen Square, London

WC1 3BG

F-X Borruat

W T Green

E M Graham

M G Sweeney

J A Morgan-Hughes

M D Sanders

Correspondence to:

Dr F-X Borruat, The National Hospital for Neurology and Neurosurgery, NeuroOphthalmology Unit, Queen Square, London WCl 3BG. Accepted for publication 19 March 1992

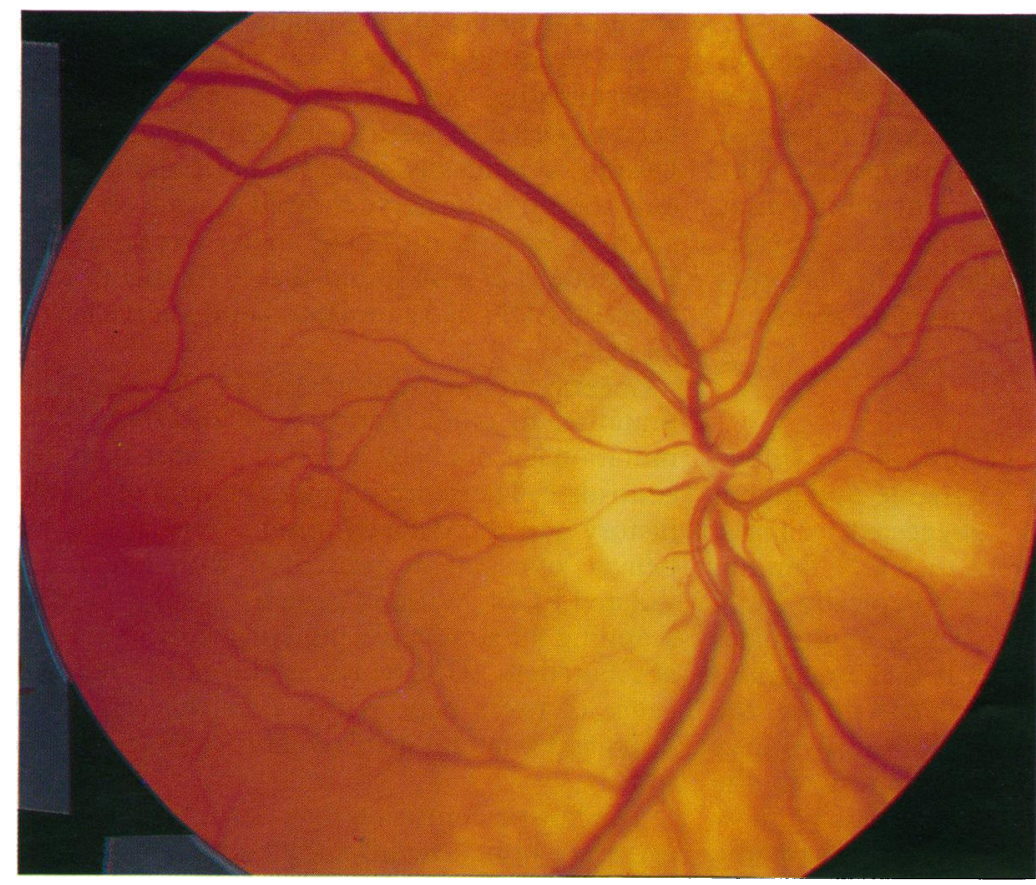

Figure 1 Right ocular fundus showing a normal sized disc without a cup with visible inferotemporal peripapillary capillaries. Medullated nerve fibres are seen nasally.

\section{Case report}

In May 1990 a previously healthy 63-year-old man noticed left visual loss accompanied by a constant, dull, left sided orbital pain. Visual function of the right eye was normal. There was no family history of visual disturbance and except for being an ex-smoker (up to 20 cigarettes a day) no vascular risk factors were found. His medical history was unremarkable. After investigations the diagnosis of left non-arteritic ION was made. Treatment with aspirin $300 \mathrm{mg} /$ day was started. Left visual loss increased over several weeks and the left orbital pain remained for 3 months. In January 1991 the patient was referred to the National Hospital for Neurology and Neurosurgery. Right visual function was normal with distance visual acuity of $6 / 4$, normal red-green colour vision (17/17 Ishihara plates), normal slit-lamp examination, and normal intraocular pressure $(14 \mathrm{~mm} \mathrm{Hg}$ ). Right fundus examination was normal except for the presence of peripapillary nasal myelinated fibres. Left visual function was reduced to counting fingers at $\mathbf{1}$ foot, absent colour vision (Ishihara plates $0 / 17$ ), and there was a left pupillary afferent defect. Left fundus examination revealed optic disc pallor.

Extraocular movements were normal. Goldmann perimetry was normal on the right but showed a central scotoma on the left side. Full-field pattern reversal visual evoked potentials (VEP) showed a normal latency (111 ms) and amplitude $(7 \cdot 6 \mu \mathrm{V})$ from the right eye and no detectable response from left eye. General examination was normal and laboratory investigations were unhelpful, including syphilis serology, CSF analysis, and computed tomography scan of head and orbits. These normal results supported the initial diagnosis of nonarteritic ION

In April 1991, 11 months after the left visual loss, the patient noted difficulty identifying distant objects and, 7 days later, difficulty reading the newspaper. On the 16 April 1991 visual acuity in the right eye was decreased to $6 / 9$ and $\mathrm{N} 8$, and red-green colour vision was also impaired (5/14 Ishihara). Goldmann perimetry was normal but tangent screen testing consistently demonstrated an inferior altitudinal loss to a small red target (3/1000 red). Fundus examination showed a normal sized disc with mild nasal swelling and visible inferotemporal capillaries (Fig 1). Fluorescein angiography showed no leakage (Fig 2). VEPs to pattern reversal showed a mild delay (120 ms) and reduced amplitude (3 $\mu \mathrm{V}$ ) potential from the right eye and no potential from left eye stimulation. Orbital MRI scanning (short time inversion recovery (STIR) sequence) revealed the presence of a high signal within the left optic nerve but no abnormal signal from the 


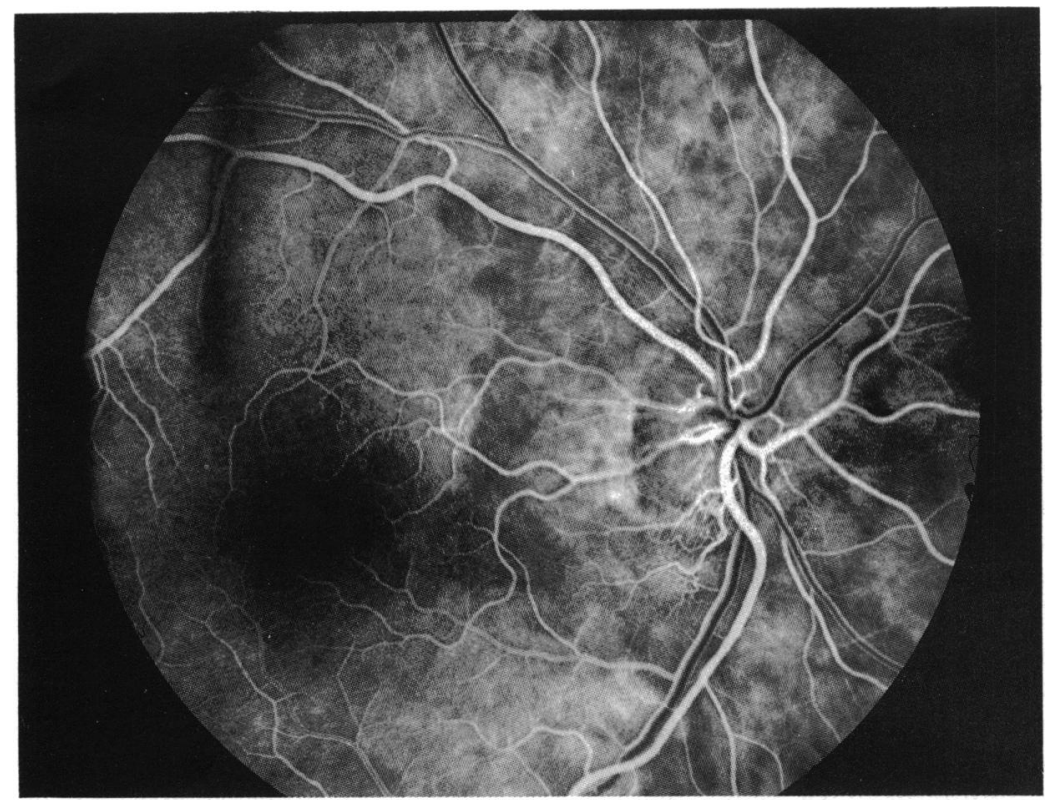

Figure 2 Fluorescein angiography of the right eye, early arteriovenous phase. Inferotemporal capillaries are visible.

right optic nerve. Repeated laboratory investigations were again normal. An electrocardiogram was also normal.
Thirteen days later vision deteriorated further on the right to $6 / 12, \mathrm{~N} 14$, and $2 / 17$ Ishihara plates. Fundus appearances were unchanged but Goldmann perimetry showed a right central scotoma. In view of this, and the suggestion of abnormal vessels on the right disc mitochondrial DNA (mtDNA) studies were undertaken to investigate the possibility of $\mathrm{LON}$ as described by Holt et al.'

Despite treatment with acetazolamide $2 \times 250$ $\mathrm{mg} /$ day, followed by prednisolone $80 \mathrm{mg} /$ day and intravenous dextran, visual loss continued in a stepwise manner over 1 month. On 15 May 1991 visual acuity of the right eye was $3 / 60$, N36, with absent, red-green colour vision. The right disc swelling had subsided and Goldmann perimetry showed enlargement of the central scotoma. Full-field pattern-reversal VEPs were undetectable in both eyes.

During this period of deteriorating vision in the better eye, optic nerve sheath decompression was considered in view of encouraging reports in progressive ischaemic optic neuropathy, ${ }^{2}$ but genetic analysis revealed the point mutation at position $11778,{ }^{3}$ which was present in more than $95 \%$ of blood, mtDNA confirming the diagnosis of LON for which surgery provides no benefit.

\section{Discussion}

Leber's optic neuropathy (LON) often exhibits maternal inheritance and a possible underlying mtDNA mutation was suggested. ${ }^{+}$Three mutations found exclusively in LON families have been reported to date. ${ }^{356}$ Typically LON affects mostly adolescent or young adult males and is rare over the age of 50 . It is characterised by painless bilateral loss of central vision, the interval between involvement of the two eyes being rarely more than a few months. In the acute stage the involved optic disc may show hyperaemia with peripapillary microangiopathy but without fluorescein leakage, and progresson to optic atrophy is usual. ${ }^{7-10}$
Worldwide, more than $50 \%$ of LON pedigrees show a point mutation of $\mathrm{mtDNA}$ at position 11778. This results in substitution of histidine for arginine in subunit 4 of complex 1 of the mitochondrial respiratory chain. ${ }^{3}{ }^{31}$ Our patient presented at 63 years of age with bilateral optic neuropathy with involvement of the second eye almost 1 year after the first. The age of onset with inferior field loss to a red target, and the absence of a relevant family history were in favour of an ION. ${ }^{1213}$ The time course suggested a progressive form of this condition. However the central scotoma and slightly swollen optic disc with a suggestion of peripapillary telangiectasia without fluorescein leakage were sufficiently suggestive of LON for the genetic analysis to be performed despite the unlikely clinical setting.

The inferior peripapillary telangiectasia may have been within normal limits but, in association with the visual loss, was attributed to the capillary dilatation seen with resolving disc oedema in ION. This raises, therefore, the importance of considering LON in any patient with telangiectasia and central visual loss.

Recently the clinical characteristics of 72 patients with LON and the 11778 mutation were reported. "Though not differing from the classic description of $\mathrm{LON}^{89}$ with regard to age at onset, visual acuity, and male predominance typical fundus findings were detected in only 30/52 patients $(58 \%)$, no patients demonstrated ECG abnormalities and, most importantly, 28 of 49 pedigrees consisted of isolated cases. Such findings contrast markedly with previous reports. ${ }^{1+}$ Indeed delayed onset LON has been reported in patients up to 70 years of age ${ }^{15}$ but this has almost always occurred in the context of a family history of blindness or within families with typical cases of LON or with asymptomatic carriers. ${ }^{1+15}$

MRI of the optic nerve using a STIR sequence revealed a lesion in the left but not in the right optic nerve. The lesion in the left optic nerve extended over $10 \mathrm{~mm}$ and was mostly posterior within the orbit. Such a length and location are more frequently seen in LON than in demyelinating optic neuritis, ${ }^{16}$ and have never been reported to occur in association with ION. Despite a clinically bilateral optic neuropathy only the left optic nerve showed a lesion on MRI. Such a discrepancy has been reported by Kermode et al who found that 3/7 patients with bilateral LON had a unilateral optic nerve lesion on MRI. ${ }^{16}$

Genetic studies showed the 11778 base pair mutation in more than $95 \%$ of mtDNA. This mutation has not been detected in more than 300 controls." Therefore despite the lack of family history and the delayed onset of visual loss we believe our patient presented with late onset isolated LON. Without genetic testing and MRI scanning the aetiology would probably have been attributed to ION which is the most frequent cause of optic neuropathy after the age of 60 years and bilateral involvement varies from 35\% to $50 \% .^{13}$

Diagnostic confusion may occur with chronic atypical optic neuropathy and this paper emphasises the value of modern genetic and radiological investigations. 
We thank Mr R Dewhirst for photographic help. The genetic studies were performed in Professor A E Harding's laboratory.

1 Holt IJ, Miller DH, Harding AE. Genetic heterogeneity and mitochondrial DNA heteroplasmy in Leber's hereditary mitochondrial

2 Sergott RC, Cohen MS, Bosley TM, Savino PJ. Optic nerve decompression may improve the progressive form of nondecompression may improve the progressive form of non-
arteritic ischemic optic neuropathy. Arch Ophthalmol 1989; 107: 1743-54.

3 Wallace DC, Singh G, Lott M, Hodge JA, Schurr TG, Lezza AMS, et al. Mitochondrial DNA mutation associated with Leber's hereditary optic neuropathy. Science 1988; 242: Leber's

4 Nikoskelainen EK, Savontaus ML, Wanne OP, Katila MJ Nummelin KU. Leber's optic neuroretinopathy, a maternally inherited disease. A genealogic study in four pedigrees. Arch Ophthaimol

5 Howell N, Kubacka MX, McCullough DA. Leber hereditary optic neuropathy: involvement of the mitochondrial ND gene and evidence for an intragenic suppressor mutation. Am 7 Hum Genet 1991; 48: 935-42.

6 Huoponen K, Vilkki J, Aula P, Nikoskelainen EK, Savontaus $M-L$. A new mtDNA mutation associated with Leber hereditary optic neuropathy. Am F Hum Genet 1991; 48: $1147-53$.

7 Miller NR. Walsh and Hoyt's clinical neuro-ophthalmology, 4th ed, Vol 1, Baltimore: Williams and Wilkins, 1982: 311-7.
8 Smith JL, Hoyt WF, Susac JO. Ocular fundus in acute Leber's optic neuropathy. Arch Ophthalmol 1973; 90: 349-

9 Nikoskelainen EK, Hoyt WF, Nummelin KU. Ophthalmoscopic findings in Leber's hereditary optic neuropathy. II. The fundus findings in the affected family members. Arch Ophthalmol 1983; 101: 1059-68.

10 Nikoskelainen EK, Hoyt WF, Nummelin KU, Schatz H. Fundus findings in Leber's hereditary optic neuropathy. 1984; 102; 981-9.

1 Newman NJ, Lott MT, Wallace DC. The clinical characteristics of pedigrees of Leber's hereditary optic neuropathy with the 11778

12 Miller NR. Walsh and Hoyt's clinical neuro-ophthalmology, 4th ed, Vol 1, Baltimore: Williams and Wilkins, 1982: 212-26. 3 Boghen DR, Glaser JS. Ischaemic optic neuropathy. Brain 1975; 98: 689-708

14 Nikoskelainen E, Nummelin K, Savontaus ML. Does sporadic Leber's disease exist? f Clin Neuro Ophthalmol 1988; 8: 225-9.

15 Seedorff T. The inheritance of Leber's disease. A genealogical follow-up study. Acta Ophthalmol 1985; 63: 135-45.

16 Kermode AG, Moseley IF, Kendall BE, Miller DH, McManus DG, McDonald WI. Magnetic resonance imaging in Leber's optic neuropathy. 7 Neurol Neurosurg Psych 1989 52: $671-4$. 